\title{
Variasi Kandungan Nutrien dalam Tambak Wanamina dengan Komposisi Jenis dan Jumlah Tegakan Mangrove yang Berbeda di Pesisir Kota Semarang
}

\section{Variation of Nutrien Concentration in Silvofishery Pond with Different Compositions of Species and Stand Abundance in Coastal Area of Semarang City}

\author{
Endah Dwi Hastuti*, Rini Budihastuti \\ Departemen Biologi, Fakultas Sains dan Matematika, Universitas Diponegoro \\ Jl. Prof. Soedarto, SH, Tembalang, Semarang \\ *Email: endah_pdil@yahoo.com
}

Diterima 16 Juni 2016 / Disetujui 10 Agustus 2016

\begin{abstract}
ABSTRAK
Keberadaan vegetasi mangrove dalam tambak wanamina berfungsi sebagai penyedia jasa lingkungan, diantaranya dalam pengendalian suplai nutrien ke dalam kolam. Penelitian ini bertujuan untuk mengkaji variasi kandungan nutrien dalam tambak wanamina dan menguji pengaruh jenis serta jumlah tegakan terhadap perubahan kandungan nutrien tambak wanamina. Penelitian dilaksanakan selama 4 bulan dengan perlakuan jenis vegetasi (A. marina; R. mucronata; Campuran) dan jumlah tegakan mangrove (5 tegakan; 10 tegakan; 15 tegakan). Kandungan nutrien yang diamati meliputi bahan organik, nitrat, nitrogen dan fosfat terlarut. Pengamatan dilakukan sebanyak 2 kali dengan jeda waktu 1 bulan. Pengujian dilakukan dengan uji-t dan ANOVA. Hasil pengamatan menunjukkan bahwa terdapat variasi kandungan nutrien dalam tambak wanamina baik pada pengamatan pertama maupun kedua. Pola perubahan kandungan nutrien bervariasi antar jenis nutrien dimana pada beberapa perlakuan ditemukan penurunan kandungan semua jenis nutrien. Hasil uji-t menunjukkan bahwa antar periode pengamatan tidak terdapat perbedaan yang signifikan terhadap kandungan bahan organik, nitrat, nitrogen dan fosfat terlarut. Hasil ANOVA menunjukkan bahwa tidak terdapat pengaruh yang signifikan terhadap kandungan nutrien dalam tambak wanamina baik pada pengamatan pertama maupun kedua. Perbedaan kandungan nutrien yang signifikan hanya diperoleh pada kandungan bahan organik pada pengamatan pertama.
\end{abstract}

Kata kunci: jenis, jumlah tegakan, mangrove, nutrien, wanamina

\begin{abstract}
The presence of mangrove vegetation in silvofishery ponds provide environmental services, such as controling nutrient supply to the ponds. This research aimed to study the variations of nutrient concentration in silvofishery pond and to analyze the effect of mangrove species and stand population on the change of nutrient concentration in silvofishery ponds. Research was conducted for 4 months involving treatments of mangrove species (A. marina; R. mucronata; Mixed) and stand population (5 stands; 10 stands; 15 stands). Concentration of nutrient observed in this research were dissolved organic matter, nitrate, nitrogen and phosphate. Observations were conducted twice with spare period of 1 month. Analysis were conducted with ttest and ANOVA. The observation result showed there were variation of nutrient concentration in silvofishery pond for both first and second observations. Change pattern of nutrients were varied among nutrient types, were some treatments showed consistent decrease for all nutrient types. Result of t-test showed there were no significant difference of dissolved organic matter, nitrate, nitrogen and phosphate resulted from first and second observations. ANOVA showed generally there were no significant efect of the treatments on the concentration of nutrient in silvofishery pond partially in first observation and second obsercation. Significant difference of nutrient concentration was achieved from organic matter in first observation.
\end{abstract}

Keywords: specie, stand population, mangrove, nutrient, silvofishery 


\section{PENDAHULUAN}

Penerapan tambak berwawasan lingkungan dengan sistem wanamina diharapkan mampu meningkatkan daya dukung lingkungan bagi kegiatan budidaya di wilayah pesisir (Suwarto et al., 2015). Upaya-upaya yang dilakukan untuk meningkatkan produktivitas pada tambak antara lain dilakukan dengan penanaman mangrove atau sering disebut dengan tambak wanamina (Purwiyanto dan Agustriani, 2014). Penanaman tersebut bertujuan untuk mencegah terjadinya kerusakan lingkungan lebih lanjut pada tambak serta meningkatkan kelayakan tambak untuk kegiatan budidaya melalui jasa-jasa lingkungan yang dihasilkan (Walters et al., 2008).

Budidaya tambak wanamina pada umumnya diterapkan dengan membagi kolam tambak menjadi dua bagian, yaitu bagian untuk kolam budidaya dan bagian untuk penanaman mangrove (Triyanto et al., 2012). Tegakan mangrove dalam tambak wanamina pada umumnya ditanam pada pintu keluar air (outlet) sehingga air yang mengalir melewati tegakan mangrove sebelum dibuang (Bengen, 2000). Keberadaan komunitas mangrove pada outlet diharapkan mampu menyaring air dan menetralisir buangan dari kegiatan budidaya (Primavera, 2006).

Berbagai penelitan telah menunjukkan bahwa penanaman mangrove pada kolam tambak dapat meningkatkan produktivitas tambak. Produksi kultivan budidaya pada umumnya rendah, namun hasil samping berupa biota ikutan menjadi pendukung produktivitas budidaya (Johnston et al., 2000). Hal ini secara tidak langsung meningkatkan pendapatan ekonomi pembudidaya meskipun hasil budidaya relatif rendah.

Dukungan mangrove dalam tambak wanamina salah satunya yaitu dalam mensuplai nutrien. Suplai nutrien yang dihasilkan dari tegakan mangrove mampu meningkatkan kelimpahan pakan alami bagi kultivan budidaya (Primavera dan Esteban, 2008). Namun, informasi mengenai bagaimana tegakan mangrove mempengaruhi kandungan nutrien dalam tambak belum banyak dikaji. Padahal, berbagai informasi terkait faktor-faktor yang mempengaruhi produktivitas tambak diperlukan untuk dapat mengoptimalkan kegiatan budidaya yang ada disamping upaya melestarikan lingkungan.

Salah satu faktor yang tidak dapat diabaikan dalam tambak wanamina yaitu jenis mangrove yang ditanam. Setiap jenis mangrove memiliki fungsi yang berbeda dalam ekosistem (Hossain dan Hoque, 2008), sehingga dampak yang ditimbulkan pada penanaman dalam tambak wanamina pun akan berbeda. Diantara berbagai jenis mangrove yang ada, mangrove jenis Avicennia marina dan Rhizophora mucronata merupakan jenis-jenis vegetasi mangrove yang paling banyak digunakan (Mwaluma, 2002). Namun, pengaruh spesifik struktur vegetasi mangrove dalam penerapannya pada tambak wanamina belum banyak diketahui. Mengingat pentingnya informasi tersebut, maka penelitian mengenai pengaruh spesifik struktur komposisi jenis mangrove terhadap kualitas lingkungan tambak perlu dilakukan.

Populasi mangrove yang ditanam pada tambak wanamina memiliki nilai penting dalam menentukan kapasitas daya dukung lingkungannya (Barbier, 2000). Semakin tinggi populasi mangrove yang ditanam, maka semakin tinggi pula daya dukung yang dimiliki. Namun, daya dukung lingkungan dalam suatu ekosistem dapat disesuaikan dengan kebutuhan sumber daya yang ada (Suprakto et al., 2014). Dalam tambak wanamina, daya dukung lingkungan yang dibutuhkan hanya sebatas pada kebutuhan untuk mendukung kegiatan budidaya yang dilakukan, dalam hal ini luas tambak yang ada (dimiliki). Hal ini dikarenakan semakin tinggi populasi mangrove yang ditanam, maka semakin luas pula kolam tambak yang digunakan untuk penanaman yang berarti luas kolam yang digunakan untuk membudidayakan ikan semakin sempit yang berakibat pada rendahnya padat tebar dan produktivitas tambak (Triyanto et al., 2012).

Perpaduan antara jenis mangrove dengan populasi tegakan mangrove merupakan komponen penting yang dapat mempengaruhi daya dukung lingkungan tambak wanamina. Upaya untuk meningkatkan produktivitas tambak atas dasar 
kedua komponen tersebut dapat diterapkan dengan mengetahui kombinasi yang paling optimal bagi ukuran tambak tertentu. Pentingnya informasi tersebut bagi penentuan rancangan tambak wanamina, maka diperlukan kajian mengenai pengaruh faktor-faktor struktur dan populasi mangrove terhadap kandungan nutrien kolam tambak. Penelitian ini dilakukan untuk menjawab pertanyaan-pertanyaan tersebut, dengan tujuan mengkaji kondisi dan perubahan kandungan nutrien dalam tambak dan menguji pengaruh jenis dan jumlah tegakan mangrove terhadap variasi kandungan nutrien tambak.

\section{METODE PENELITIAN}

Penelitian dilaksanakan di kawasan tambak Desa Mangunharjo, Kecamatan Tugu Kota Semarang selama 4 bulan. Desain penelitian meliputi 9 perlakuan dengan 2 faktor, yaitu faktor struktur vegetasi mangrove dan faktor populasi mangrove. Tegakan mangrove ditanam pada intake tambak dengan kombinasi vegetasi berupa $A$. marina (V1), R. mucronata (V2) dan campuran (V3), sedangkan tegakannya yaitu sebanyak 5 tegakan (L1), 10 tegakan (L2) dan 15 tegakan
(L3). Tegakan mangrove yang terdapat dalam tambak wanamina yang diteliti yaitu berupa tegakan semai. Kolam tambak yang digunakan untuk pemeliharaan ikan memiliki ukuran 5 x 5 $\mathrm{m}^{2}$.

Pengumpulan data dilaksanakan sebanyak 2 kali pengamatan dengan jeda antar pengamatan selama 1 bulan. Parameter-parameter yang diamati dalam penelitian ini meliputi kandungan bahan organik, nitrat, nitrogen dan fosfat terlarut. Analisa data dilakukan untuk mengetahui ada / tidaknya pengaruh perlakuan tegakan mangrove terhadap kandungan nutrien tambak dilakukan dengan uji-t dan ANOVA.

\section{HASIL DAN PEMBAHASAN}

Hasil pengujian laboratorium terhadap kandungan nutrien terlarut dalam kolam tambak menunjukkan adanya variasi baik pada pengamatan I maupun pada pengamatan II. Hasil pengujian menunjukkan terdapat variasi perubahan terhadap kandungan nutrien antar pengamatan. Hasil pengujian kandungan nutrien dalam tambak wanamina secara rinci disajikan pada Tabel 1 .

Tabel 1. Kandungan Nutrien Terlarut dalam Kolam Tambak Wanamina

\begin{tabular}{cccccccccc}
\hline \multirow{2}{*}{ No. } & \multirow{2}{*}{ Petak } & \multicolumn{2}{c}{ Bahan Organik (mg/l) } & \multicolumn{2}{c}{ Nitrat $\mathbf{( m g / l )}$} & \multicolumn{2}{c}{ Nitrogen $\mathbf{( m g / l )}$} & \multicolumn{2}{c}{ Fosfat (mg/l) } \\
\cline { 3 - 9 } & & I & II & I & II & I & II & I & II \\
\hline 1 & L1V1 & 12,540 & 14,050 & 3,450 & 5,045 & 4,090 & 6,574 & 0,325 & 0,410 \\
2 & L1V2 & 10,608 & 9,552 & 4,027 & 3,725 & 4,882 & 4,220 & 0,414 & 0,329 \\
3 & L1V3 & 9,550 & 8,020 & 4,870 & 5,160 & 5,030 & 5,829 & 0,337 & 0,290 \\
4 & L2V1 & 9,039 & 7,535 & 5,339 & 4,625 & 6,015 & 5,255 & 0,419 & 0,338 \\
5 & L2V2 & 12,740 & 10,120 & 5,120 & 5,710 & 5,930 & 6,046 & 0,450 & 0,510 \\
6 & L2V3 & 13,030 & 11,449 & 6,773 & 3,925 & 7,332 & 4,485 & 0,355 & 0,465 \\
7 & L3V1 & 7,563 & 8,120 & 3,806 & 3,460 & 4,385 & 4,710 & 0,420 & 0,438 \\
8 & L3V2 & 6,170 & 5,390 & 6,395 & 5,332 & 6,836 & 6,150 & 0,375 & 0,425 \\
9 & L3V3 & 8,439 & 5,434 & 4,720 & 4,135 & 5,140 & 5,829 & 0,339 & 0,344 \\
\hline
\end{tabular}

Keterangan : I, II = periode pengamatan

$\mathrm{L} 1 \mathrm{~V} 1=A$. marina 5 tegakan $\quad \mathrm{L} 2 \mathrm{~V} 1=$ A. marina 10 tegakan

$\mathrm{L} 1 \mathrm{~V} 2=R$. mucronata 5 tegakan

L1V3 = Campuran 5 tegakan
L2V2 $=R$. mucronata 10 tegakan L2V3 = Campuran 10 tegakan
$\mathrm{L} 2 \mathrm{~V} 1=A$. marina 15 tegakan

$\mathrm{L} 2 \mathrm{~V} 2=R$. mucronata 15 tegakan L2V3 = Campuran 15 tegakan 
Hasil pengamatan sebagaimana disajikan pada Tabel 1 menunjukkan bahwa kandungan nutrien baik bahan organik, nitrat, nitrogen mapun fosfat terlarut antar pengamatan mengalami penurunan pada sebagian perlakuan. Tabel 1 menunjukkan bahwa pada perlakuan L1V1 tidak terjadi penurunan kandungan nutrien pada semua parameter yang diamati. Sebaliknya, pada perlakuan L1V2 dan L2V1 justru mengalami penurunan pada semua parameter yang diamati. Perlakuan L1V3 hanya mengalami penurunan pada kandungan bahan organik dan fosfat, sedangkan L2V2 hanya mengalami penurunan pada kandungan bahan organik saja. Perlakuan L2V3 dan L3V2 mengalami penurunan pada kandungan bahan organik, nitrat dan nitrogen, sedangkan perlakuan L3V1 mengalami penurunan pada kandungan nitrat saja sementara perlakuan L3V3 mengalami penurunan pada kandungan bahan organik dan nitrat.

Hasil uji-t kandungan nutrien antar periode pengamatan menunjukkan bahwa tidak terdapat perbedaan yang signifikan dari kandungan bahan organik, nitrat, nitrogen dan fosfat. Hasil ANOVA terhadap kandungan nutrien menunjukkan bahwa secara umum tidak terdapat pengaruh yang signifikan dari perlakuan yang diterapkan. Berdasarkan hasil pengujian, hanya kandungan bahan organik pada awal pengamatan yang secara signifikan berbeda berdasarkan perlakuan populasi tegakan mangrove. Sementara parameter lain tidak berbeda secara signifikan baik berdasarkan perlakuan jenis vegetasi maupun populasi tegakan pada inlet tambak wanamina. Kandungan bahan organik paling rendah pada perlakuan dengan 15 tegakan yang secara signifikan berbeda dengan perlakuan dengan 5 tegakan dan 10 tegakan, sedangkan antara perlakuan dengan 5 tegakan dan 10 tegakan tidak berbeda secara signifikan.

Hasil penelitian menunjukkan bahwa kandungan nutrien terlarut dalam kolam tambak dapat mengalami perubahan, baik peningkatan maupun penurunan. Perubahan kandungan nutrien dalam kolam tambak dapat disebabkan oleh adanya variasi temporal kualitas lingkungan (Affan et al., 2005). Perubahan kondisi lingkungan secara temporal berdampak pada tingkat suplai nutrien ke dalam kolam tambak yang salah satunya dipengaruhi oleh keberadaan tanaman sebagai produsen serasah (Gotelli et al., 2008). Menurut Litchman et al. (2004), kandungan nutrien dalam perairan dimanfaatkan oleh fitoplankton. Penyerapan nutrien oleh fitoplankton bersifat dinamik berdasarkan kondisi lingkungan perairan (Bonachela et al., 2011).

Kandungan nutrien dalam kolam tambak secara dinamik mengalami perubahan (Islam et al., 2004). Keseimbangan nutrien dalam kolam tambak menunjukkan berapa besar penyusutan kandungan nutrien yang terpakai dalam tambak. Menurut Li dan Yakupitiyage (2003), kandungan pakan alami dalam tambak juga dipengaruhi oleh adanya input pakan buatan. Dinamika kualitas lingkungan dapat bervariasi berdasarkan ruang dan waktu.

Suplai nutrien dalam tambak pada umumnya berasal berbagai sumber, antara lain dari aliran air yang masuk ke dalam tambak, sisa pakan dan kotoran ikan (Muendo et al., 2014). Suplai nutrien tambahan pada tambak konvensional pada umumnya diperoleh dari sisa-sisa pakan yang diberikan, sedangkan pada tambak wanamina diperoleh dari proses dekomposisi serasah mangrove yang menghasilkan bahan organik dan nutrien seperti nitrogen dan Fosfor (Gatune et al., 2012). Penurunan kandungan nutrien terjadi pada saat air surut sehingga nutrien terlarut dalam air terbawa keluar dari kolam tambak bersama aliran (Muendo et al., 2014). Nutrien juga mengalami penyusutan akibat adanya konsumsi oleh organisme air seperti fitoplankton, alga, atau tanaman air lain yang membutuhkan nutrien untuk tumbuh dan berkembang (Anderson et al., 2002).

Menurut Cotano dan Villate (2006), bahan organik bersumber dari pemukiman dan proses biokimia yang terjadi dalam ekosistem. Kegiatan manusia menyumbang bahan organik yang cukup besar bagi muara sungai, namun pada umumnya dalam bentuk yang belum terdekomposisi dengan baik. Sementara menurut McCallister et al. (2006), tingkat akumulasi bahan organik dalam perairan dipengaruhi oleh berbagai faktor antara lain keberadaan struktur fisik yang dapat menahan aliran bahan organik. Hal ini menunjukkan bahwa keberadaan tegakan mangrove dalam tambak juga 
dapat berperan dalam proses akumulasi bahan organik.Adanya perbedaan kandungan bahan organik dalam tambak dipengaruhi oleh laju akumulasi dan laju dekomposisinya.

Proses dekomposisi bahan organik menghasilkan nutrien seperti $\mathrm{C}, \mathrm{N}, \mathrm{P}, \mathrm{K}, \mathrm{Ca}, \mathrm{Mg}$ dan sebagainya (Cottanio et al., 2008). Sehingga kandungan bahan organik dalam tambak salah satunya dipengaruhi oleh laju dekomposisi bahan organik. Selain proses dekomposisi bahan organik, pemupukan juga menjadi sumber nutrien bagi tambak. Limbah buangan dari aktivitas manusia juga menjadi sumber bagi nutrien perairan. Namun, jumlahnya seringkali berlebih sehingga cenderung menjadi pencemar bagi perairan (Martins et al., 2010).

Hasil penelitian menunjukkan bahwa tidak terdapat pengaruh yang signifikan dari jumlah dan komposisi jenis tegakan mangrove terhadap variasi kandungan nutrien dalam kolam tambak wanamina. Hal ini disebabkan karena tegakan mangrove masih berusia muda (semai) sehingga belum memberikan fungsi biologis yang signifikan. Fungsi tegakan semai dalam tambak wanamina hanya berupa fungsi fisik, yaitu peredaman arus dan penjebakan sedimen dan bahan organik. Menurut Kristensen et al. (2008), ekosistem mangrove memiliki fungsi sebagai penahan sedimen dan nutrien serta mengendalikan distribusinya ke ekosistem di sekitarnya.

\section{SIMPULAN}

Kandungan nutrien dalam tambak wanamina mengalami fluktuasi pada semua perlakuan, yaitu berupa kenaikan dan penurunan konsentrasi nutrien terlarut antar periode pengamatan. Pengaruh perlakuan jumlah dan komposisi tegakan mangrove secara umum tidak berpengaruh terhadap kandungan nutrien dalam kolam tambak, parameter yang secara signifikan bervariasi yaitu kandungan bahan organik pada pengamatan pertama.

\section{UCAPAN TERIMA KASIH}

Peneliti mengucapkan terima kasih kepada Ketua Jurusan Biologi dan Dekan Fakultas Sains dan Matematika atas pendanaan penelitian ini melalui Hibah Penelitian Jurusan Biologi Fakultas Sains dan Matematika Universitas Diponegoro tahun anggaran 2015.

\section{DAFTAR PUSTAKA}

Affan, A., A.S. Jewel, M. Haque, S. Khan dan J.B. Lee. 2005. Seasonal Cycle of Phytoplankton in Aquaculture Ponds in Bangladesh. Algae 20(1): 43 - 52.

Anderson, D.M., P.M. Glibert dan J.M. Burkholder. 2002. Harmful Algal Blooms and Eutrophication: Nutrient Sources, Composition and Consequences. Estuaries 25(4b): $704-706$.

Barbier, E.B. 2000. Valuin the Environment As Input: Review of Applications to Mangrove-Fishery Linkages. Ecological Economics 35: $47-61$.

Bengen, D.G. 2000. Pengenalan dan Pengelolaan Ekosistem Mangrove. PedomanTeknis, PKSPL IPB, Bogor

Bonachela, J.A., M. Raghib dan S.A. Levin. 2011. Dynamic Model of Flexible Phytoplankton Nutrient Uptake. PNAS 108(51): 20633 20638. Doi: 10.1073/pnas.1118012108

Cattanio, J.H., R. Kuehne dan P.L.G. Vlek. 2008. Organic Material Decomposition and Nutrient Dynamics in A Mulch System Enriched with Leguminous Trees in the Amazon. R. Bras. CI. Solo 32: 1073 1086.

Cotano, U. dan F. Villate. 2006. Anthropogenic Influence on the Organic Fraction of Sediments in Two Contrasting Estuaries: A Biochemical Approach. Marine Pollution Bulletin 52: $404-414$. doi:10.1016/j.marpolbul.2005.09.027 
Gatune, C., A. Vanreusel, C. Cnudde, R. Ruwa, P. Bossier dan M.D. Troch. 2012. Decomposing Mangrove Litter Supports A Microbial Biofilm with Potential Nutritive Value to Penaeid Shrimp Post Larvae. Journal of Experimental Marine Biology and Ecology 426 - 427: 28 - 38. doi:10.1016/j.jembe.2012.05.015

Gotelli, N.J., P.J. Mouser, S.P. Hudman, S.E. Morales, D.S. Ross dan A.M. Ellison. 2008. Geographic Variation in Nutrient Availability, Stoichiometry, and Metal Concentrations of Plants and Pore-Water in Ombrotrophic Bogs in New England, USA. Wetlands 28(3): $827-840$.

Hossain, M. dan A.K.F. Hoque. 2008. Litter Production and Decomposition in Mangroves - A Review. Indian Journal of Forestry 31(2): $227-238$.

Islam, M.L., M.J. Alam, S. Rheman, S.U. Ahmed dan M.A. Mazid. 2004. Water Quality, Nutrient Dynamics and Sediment Profile in Shrimp Farms of the Sundarbans Mangrove Forest, Bangladesh. Indian Journal of Marine Sciences 33(2): 170 176.

Johnston, D., N.V. Trong, D.V. Tien dan T.T. Xuan. 2000. Shrimp Yields and Harvest Characteristics of Mixed Shrimp Mangrove Forestry Farms in Southern Vietnam: Factors Affecting Production. Aquaculture 188: $263-284$.

Kristensen, E., S. Bouillon, T. Dittmar dan C. Marchand. 2008. Organic Carbon Dynamics in Mangrove Ecosystem: A Review. Aquatic Botany 89: $201-219$. doi:10.1016/j.aquabot.2007.12.005

Li, L. dan A. Yakupitiyage. 2003. A Model for Food Nutrient Dynamics of SemiIntensive Pond Fish Culture. Aquaculture Engineering 27: $9-38$.

Litchman, E., C.A. Klausmeier dan P. Bossard. 2004. Phytoplankton Nutrient Competition Under Dynamic Light Regimes. Limnol. Oceanogr. 49(4-2): 1457 - 1462.
Martins, A.P., C.B. Reissmann, M.R.T. Boeger, E.B. De Oliveira dan N. Favaretto. 2010. Efficiency of Polygonum hydropiperoides for Phytoremediation of Fish Pond Effluents Enriched with $\mathrm{N}$ and P. J. Aquat. Plant. Manage. 48: 116 - 120.

Mc.Callister, S.L., J.E. Bauer, H.W. Ducklow dan E.A. Canuel. 2006. Sources of Estuarine Dissolved and Particulate Organic Matter: A Multi-Tracer Approach. Organic Geochemistry 37: $454 \quad-468$. doi:10.1016/j.orggeochem.2005.12.005

Muendo, P.N., M.C.J. Verdegem, J.J. Stoorvogel, A.Milstein, E.-N. Gamal, P.M. Duc dan J.A.J. Verreth. 2014. Sediment Accumulation in Fish Ponds; Its Potential for Agricultural Use. International Journal of Fisheries and Aquatic Studies 1(5): 228 -241 .

Mwaluma, J. 2002. Pen Culture of the Mud Crab Scylla serrata in Mtwapa Mangrove System, Kenya. Western Indian Ocean J. Mar. Sci. 1(2): 127 - 133.

Primavera J. H., and J. M. A. Esteban. 2008. AReview of Mangrove Rehabilitation in thePhilippines: Successes, Failures and FutureProspects. Wetlands Ecology and Management 16:345 - 358.

Primavera, J.H. 2006. Overcoming the Impacts of Aquaculture on the Coastal Zone. Ocean \& Coastal Management 49: 531 - 545. doi:10.1016/j.ocecoaman.2006.06.018

Purwiyanto, A.I.S. dan F. Agustriani. 2014. Effect of Silvofishery on Ponds Nutrient Levels. Ilmu Kelautan 19(2): 81 - 87.

Suprakto, B., Soemarno, Marsoedi dan D. Arfiati. 2014. Development of Mangrove Conservation Area Based on Land Suitability and Environmental Carrying Capacity (Case Study from Probolonggo Coastal Area, East Java, Indonesia). International Journal of Ecosystem 4(3): $107 \quad-\quad 118 . \quad$ DOI: 10.5923/j.ije.20140403.02 
Suwarto, A.M. Lahjie, A. Ruchaemi, B.D.A.S. Simorangkir dan F. Mulyadi. 2015. Ecological Aspect of Non Productive Fishponds at Mahakam Delta Area: Revitalization with Silvofishery System. Global Journal of Agriculture Research 3(1): $27-37$.

Triyanto, N.I. Wijaya, T. Widiyanto, I. Yuniarti, F. Setiawan dan F.S. Lestari. 2012. Pengembangan Silvofishery Kepiting Bakau (Scylla serrata) dalam Pemanfaatan Kawasan Mangrove di Kabupaten Berau, Kalimantan Timur. Prosiding Seminar Nasional Limnologi VI. Pp: 739 - 751

Walters, B.B., P. Ronnback, J.M. Kovacs, B. Crona, S.A. Hussain, R. Badola, J.H. Primavera, E. Barbier dan F. DahdouhGuebas. 2008. Ethnobiology, SocioEconomics and Management of Mangrove Forests: A Review. Aquatic Botany 89: 220-230 